\title{
Do mistakes acceptance foster innovation? Polish and US cross-country study of tacit knowledge sharing in IT
}

\author{
Wioleta Kucharska
}

\begin{abstract}
Purpose - This study aims to understand and compare how the mechanism of innovative processes in the information technology (IT) industry - the most innovative industry worldwide - is shaped in Poland and the USA in terms of tacit knowledge awareness and sharing driven by a culture of knowledge and learning, composed of a learning climate and mistake acceptance.

Design/methodology/approach - Study samples were drawn from the IT industry in Poland $(\mathrm{n}=350)$ and the USA ( $\mathrm{n}=370)$ and analyzed using the structural equation modeling method.

Findings - True learning derives from mistake acceptance. As a result of a risk-taking attitude and critical thinking, the IT industry in the USA is consistently innovation-oriented. Specifically, external innovations are highly correlated with internal innovations. Moreover, a knowledge culture supports a learning culture via a learning climate. A learning climate is an important facilitator for learning from mistakes.

Originality/value - This study revealed that a high level of mistake acceptance stimulates a risk-taking attitude that offers a high level of tacit knowledge awareness as a result of critical thinking, but critical thinking without readiness to take a risk is useless for tacit knowledge capturing.
\end{abstract}

Keywords Tacit knowledge, Organizational learning, Innovations, Company culture, Critical thinking, Learning climate, Risk taking, Mistake acceptance

Paper type Research paper

\section{Introduction}

This paper concentrates on the innovativeness processes of the information technology (IT) industry, as its development is having a tremendous effect on society as a whole through changes to the way people think, work, live and interact with one another. Technological innovations support assimilating and organizing diverse technological inputs to create original inventions or facilitate successful new product development. This study aims to understand and compare how the mechanism (causal effects) of innovative processes is shaped by knowledge and learning culture in the IT industry - the most innovative industry worldwide. All knowledge is rooted in tacit knowledge (Polanyi, 1966), and several studies have explored tacit knowledge as an innovativeness power. For example, Sheng (2019) and Ganguly et al. (2019) found that tacit knowledge contributes to innovation capabilities. However, what is still needed is understanding of how knowledge and learning culture influence the processes of tacit knowledge awareness and sharing and contribute to internal and external innovativeness. Based on empirical research, knowing exactly how a learning culture composed of a learning climate and mistake acceptance (Kucharska and Bedford, 2020) shapes tacit knowledge awareness and sharing in the context of organizational internal and external innovativeness may be critical for knowledge management. Mistakes are often ignored, yet they may be a precious learning resource. This study aims to deal with this issue.
Wioleta Kucharska is based at Department of Management, Faculty of Management and Economics, Gdansk University of Technology, Gdansk, Poland.
Received 28 December 2020 Revised 19 February 2021 Accepted 8 March 2021

(C) Wioleta Kucharska Published by Emerald Publishing Limited. This article is published under the Creative Commons Attribution (CC BY 4.0) licence. Anyone may reproduce, distribute, translate and create derivative works of this article (for both commercial \& non-commercial purposes), subject to full attribution to the original publication and authors. The full terms of this licence may be seen at http:// creativecommons.org/licences/ by/4.0/legalcode

Funding Acknowledgement: The presented research is a result of the project Tacit Knowledge Sharing Influence on Innovativeness. The Sector Analysis No. UMO-2018/31/D/ $\mathrm{HS} 4 / 02623$ is financed by the funds of the National Science Center of Poland (Narodowe Centrum Nauki-NCN). 
Undoubtedly, tacit knowledge is a fantastic source of innovation (Ganguly et al., 2019; Jisr and Maamari, 2017; Pérez-Luño et al., 2019). This knowledge is novel and thus beneficial for organizations focused on innovativeness. This form of expertise is specific - it is produced and stored in people's minds and is personal rather than communal. In its early stage, it is difficult to be aware of or articulate this knowledge, and its development requires social interactions (Insch et al., 2008). One of the earliest distinctions between explicit and tacit knowledge comes from sociology. Polanyi (1966) noted that "we know more, than we can tell" (p. 4), and introduced a specific - tacit kind of knowledge. But tacit knowledge was applied specifically to knowledge management by Nonaka and Takeuchi (1995). Nonaka (1994) conceptualized tacit knowledge in the following two ways:

1. a cognitive aspect including all experiential inputs needed to create an idea; and

2. a technical aspect comprised of new learned skills thanks to acting (learning by doing).

More recently, the two-part categorization has had suggested extensions, including the third aspect of effectuation or "what I know" (Jisr and Maamari, 2017) and an aspect of socialization, characterized by task-related interaction and social interaction (Insch et al., 2008). The latter view makes explicit the idea that, even though tacit knowledge tends to be gained through personal experience and might be learned through repeated on-the-job activities, it can also be obtained by means of guidance from another willing to share their knowledge (Olaisen and Revang, 2018).

Asher and Popper's (2019) recent conceptualization of an "onion" model posits different layers of tacit knowledge and a description of knowledge as a matter of degree along a single axis, where knowledge is more explicit at one end and more tacit at the other end, with elements of both forming the middle. The forms of knowledge range from more explainable and closer to explicit knowledge to virtually impossible to explain and only demonstrable, at the furthest reaches of tacit knowledge (perhaps verging on insight/ intelligence). Ryan and O'Connor (2013) examined software project teams and claimed that tacit knowledge is acquired and shared directly through good quality social interactions between team members. Koriat and Gelbard (2014) studied IT teams and claimed that exchanging tacit knowledge is a real challenge today. Tacit knowledge is personal, therefore sharing it cannot be formalized or forced (Kucharska and Kowalczyk, 2016). Thus, understanding the acts of acquiring and sharing tacit knowledge are crucial for innovativeness in IT. This study aims to explore this issue.

Without organizational learning, there can be no sustainable organizational innovativeness in response to the changing world (Choi and Chandler, 2020; Björkdahl and Börjesson, 2012; Bligh et al., 2018). There is also no learning without mistakes (Van Dyck et al., 2005). All people make mistakes, but especially those who actively seek new horizons, break conventions and want to learn and grow, as observed in the IT industry. Therefore, this study examines the cultural factors of learning climate and mistake acceptance (Kucharska and Bedford, 2020) as a potential stimulus of tacit knowledge capturing. The recent studies by Farnese et al. $(2019,2020)$ demonstrated the importance of cultural orientation to learn from errors. If organizational culture is important for mistakes, the national cultural context must also be influential. Therefore, this study presents a comparison of Poland and the USA in the context of organizations gaining tacit knowledge from mistakes to increase innovativeness. This comparison is significant, given that the USA is one of the most technologically innovative countries. In contrast, Poland is a post-soviet nation that, however fast-growing is only 30 years free from the soviet system. So, this long-lasting national experience of the soviet system might still be reflected in business culture. Such harmful events may have lasting effects for generations, which could influence both focuses of this study - a learning culture that accepts mistakes and knowledge sharing - as both these factors require organizational safety (Andersson et al., 2020). Thus, this study aims to understand and compare how the mechanism of innovative processes in the IT industry - 
the most innovative industry worldwide - is shaped in Poland and in the USA in terms of tacit knowledge awareness and sharing driven by a culture of knowledge and a learning culture composed of a learning climate and mistakes acceptance.

\section{Conceptual framework}

Errors, mistakes and failures - all refer in some manner to actions that have unintended effects - and the approaches to perceiving, defining and managing them differ, depending on the industry lens. Errors relate to a deviation from norms, and this term is often used in error management studies in production (Seifried and Höpfer, 2013; Love et al., 2018; Seckler et al., 2017). A mistake is usually associated with a wrong decision (Mangels et al., 2006) and could be caused by, for instance, data errors. Meanwhile, failure is conceptualized as the lack of the desired results, and it includes avoidable mistakes and the unavoidable negative outcomes of risk taken, such as in experiments or new venture creation (Cannon and Edmondson, 2001; Politis and Gabrielsson, 2009). Therefore, failure could be equally attributable to negligence and diligence when acting under uncertain conditions, characteristic of early-stage entrepreneurs (e.g. those launching startups) or mature entrepreneurs seeking new business opportunities. Senders and Moray (1991) described an error as the act that is "not intended by the actor; not desired by a set of rules or an external observer, or that led the task or system outside its acceptable limits" (p. 25). Frese and Keith (2015) defined it as "unintended deviations from plans goals, or adequate feedback processing, as well as incorrect actions resulting from lack of knowledge" (p. 662). Error management is defined as an organizational strategy to minimize the negative consequences of errors through early detection and correction and to prevent errors through learning (Van Dyck et al., 2013). In this regard, the aviation industry (Hagen, 2013) and the construction industry (Love et al., 2013, 2015, 2106, 2018) have adopted this strategy. In addition, the health-care industry offers many positive examples and ideas related to error management and learning from errors (Fischer et al., 2006; Kalender et al., 2020; Metcalfe, 2017; Van Dyck et al., 2013; Waeschle et al., 2015). Kalender et al. (2020) and Anderson and Abrahamson (2017), similarly to Zhao and Olivera (2006), noted that a critical problem regarding organizational learning from mistakes is the lack of reporting, and therefore, they highlighted the need for change in organizational attitudes toward errors. Further, Ferguson (2017) and Robertson and Long (2018) asserted that the lack of reporting in the health-care field may be caused by the organizational "culture of blame and shame" (p. 404). If mistakes are hidden, they cannot serve as lessons for anyone except those who make them. Thus, Mohsin et al. (2019) suggested that error reporting should be a standard taught at medical school.

Many positive examples of learning from mistakes have emerged from entrepreneurship studies, that is, from entrepreneurial learnings from business failures (Cardon et al., 2011; Cope, 2011; Eggers and Song, 2015; McGrath, 1999; Politis and Gabrielsson, 2009; Shepherd, 2003; Yamakawa and Cardon, 2015). Recent studies on the hospitality industry (Guchait et al., 2016, 2018; Pasamehmetoglu et al., 2017; Jung and Yoon, 2017; Wang et al., 2020) simplified the organizational attitude toward errors to the primary question: Should mistakes at work be tolerated? As they observed that error tolerance yields positive outcomes for employees, such as psychological safety, self-efficacy, supportive employee behaviors, employee learning and increased error reporting rates - they asserted that it should be tolerated. Moreover, the organizational gains through reporting are work engagement and service recovery performance.

Frese and Keith (2015) and Weinzimmer and Esken (2017) studied learning from mistakes and revealed that the essence of deep organizational learning is to identify and modify errors. It is visible in the error management approach in IT.

Error management studies on IT are classified into four categories - methods, people, tools and requirements (Anu et al., 2018; De Felice and Petrillo, 2017) - and focus on error 
detection and correction, often by applying statistical methods (Challa et al., 2020; Di Sanzo et al., 2021; Singh and Walia, 2020). Software development is a knowledge-intensive process, and in this field, employees' cognitive failures are the primary causes of software errors (Balaji and Murugaiyan, 2012). Therefore, learning from mistakes in this field is focused on reflections throughout the software development lifecycle (i.e. analyzing errors in requirements, coding and testing) by adopting, for instance, the $V$ model for testing (Akinsola et al., 2020) or an approach to improve the software development process, such as the capability maturity model (Huang and Liu, 2017) or the agile retrospective process as part of the Scrum method (Annosi et al., 2020; Gaikwad et al., 2019). Agile learning is supported by a learning culture in IT (Tripathi et al., 2020), and this support is crucial for continuous innovation (Denning, 2013).

Innovation in the IT industry in the context of organizational culture has attracted much attention recently (Abubakre et al., 2020; Bourdeau et al., 2020; Fan et al., 2019; Nguyen et al., 2019). However, none of the studies has considered the culture of knowledge or learning in the context of tacit knowledge. As tacit knowledge is a source of innovation (Kodama, 2019) and a culture that enables creating a channel of knowledge flows supports tacit knowledge sharing (Mabey et al., 2012; Mabey and Zhao, 2017), such studies are important. Moreover, Cabrilo et al. $(2018,2020)$ demonstrated the direct and positive influence of intellectual capital on organizational innovativeness in IT. Saint-Onge (1996) noted that tacit knowledge influences organizational intellectual capital. Therefore, tacit knowledge is perceived as vital for innovativeness (Ganguly et al., 2019; Pérez-Luño et al., 2016, 2019). Therefore, to fill this literature gap, this study focuses on how tacit knowledge can be captured in the IT industry driven by a culture of knowledge and a learning culture composed of a learning climate and mistake acceptance.

Mistakes are often perceived as an unwelcome side effect of human learning; however, they can be a precious experience resource enabling learning, if they are accepted. We cannot learn from mistakes if we do not accept them. Nonaka and Takeuchi (2019), developing the SECI approach that they proposed in 1994, stressed that continuous innovation results when companies constantly and repeatedly create new knowledge. Mistakes seem to be a good stimulus for constant learning as a result of the comparably easy access to mistakes, given that we all make them. Knowledge capture is a prerequisite for enhancing innovation and performance (Rutten et al., 2016). Several studies have highlighted that knowledge sharing fosters idea generation among employees, which enables innovation (Henri, 2016) and effective organizational change (Park and Kim, 2015). However, there is a lack of studies exploring the capture of tacit knowledge from mistakes to support organizational innovativeness. This study aims to fill this gap.

\section{Knowledge culture and constant learning culture}

Islam et al. (2015) described knowledge culture as conditions that support the broad flow of knowledge in an organization. Knowledge culture is a base for organizational development in a knowledge-driven economy (Powell and Snellman, 2004); however, passive knowledge is insufficient to bring business value. Knowledge in use (in action) is needed. As Rothberg and Erickson (2017) stated, knowledge in action requires strategic and tactical intelligence, which derives from the organization's intellectual capital and knowledge processes. Nonaka and Takeuchi (2019) confirmed the SECl approach when they developed the SECI model that they had presented in their 1994 study. They noted that continuous innovation results from companies constantly and repeatedly creating new knowledge, disseminating the knowledge and converting the knowledge into explicit knowledge and action. To achieve this, the set of knowledge routines visible in the organizational pattern of behaviors must be developed. Such a pattern of knowledge-related behaviors determines a knowledge culture of the company. Culture is the "key ingredient in shifting from knowledge to intelligence" (Rothberg and Erickson, 2017, p. 283). Mueller $(2014,2018)$ noted that 
knowledge culture and learning culture are both vital, but learning culture is essential for constant development. Garvin (1993, p. 80) defined learning culture as "an organization skilled at creating, acquiring, and transferring knowledge and modifying its behavior to reflect new knowledge and insights." Thus, a desire to possess knowledge is a motivation for learning. Learning fosters the knowledge development, but a knowledge culture must enhance the positive attitude and motivation among employees to learning routines. Kucharska and Bedford (2020) defined constant learning culture as comprising a learning climate and mistakes acceptance. Hence, it can be concluded that a knowledge culture supports both of learning culture's components. Zappa and Robins (2016) noted that the essence of organizational learning is to identify and modify errors. Therefore, based on all the above information, the following hypotheses were proposed:

H1a. Knowledge culture positively influences the learning climate.

H1b. Knowledge culture positively influences the acceptance of mistakes.

Moreover, Örtenblad (2002) noted that learning climate encourages learning through trial and error and enhancing reflection. Therefore, $H 2$ was developed as follows:

H2. A constant learning climate positively influences mistakes acceptance.

\section{Constant learning culture and tacit knowledge}

A constant learning culture is composed of the overall learning climate and mistakes acceptance as an internal part of the learning process. We cannot learn from mistakes without accepting them. The studies by Farnese et al. $(2019,2020)$ stressed the importance of cultural orientation to learn from errors. Moreover, Vanderheiden and Mayer (2020) highlighted the cultural factor of mistake perception. Mistakes are probably one of the most common human experiences and, equally, one of the least appreciated, despite being vital for learning (Guchait et al., 2015; Harteis et al., 2008; Simonsson and Heide, 2018). There is no learning without mistakes (Van Dyck et al., 2005). Thus, considering all the above, it is assumed that learning from mistakes is an opportunity to gain tacit knowledge. From SaintOnge (1996) perspective, tacit knowledge is organizational knowledge on a greater level, given its contribution to novelty creation. It is composed of intuition, personal beliefs, assumptions, attitudes, values and overall experiences at the individual level. As Polanyi (1966) stated, we know more than we can tell, and we know more than we can logically explain (Dörfler and Ackermann, 2015; Koestler, 1971). It is easier to sense or observe tacit knowledge than to describe it during its very early stage. Asher and Popper's (2019) "onion" model introduced various layers of tacit knowledge related to tacitness degrees. From their point of view, three layers are focal: a hidden practical layer, a tacit reflective layer and a demonstrated layer. This suggests that the level of tacitness determines awareness and sharing. Tacit knowledge sharing requires trust collaboration and an overall learning climate and psychological safety (Kucharska and Kowalczyk, 2016; Andersson et al., 2020). Therefore, the mistakes acceptance component of the constant learning culture, alongside learning climate, is vital for tacit knowledge awareness. Based on the above elaboration, hypotheses were developed as follows:

H3a. A learning climate facilitates tacit knowledge awareness.

H3b. Mistakes acceptance facilitates tacit knowledge awareness.

Olaisen and Revang (2018) advocated for a three-level model that reveals the essence of tacit knowledge awareness and sharing. The levels are representable knowing, nonrepresented knowing and non-representable knowing. In the current research, tacit awareness is presented as the stage at which tacit knowledge evolves to a stage enabling the articulation of new ideas through metaphors, demonstrations, contextual storytelling or sharing impressions. Therefore, in its early stage, tacit knowledge can be called "intuitive knowledge." Following El-Den and Sriratanaviriyakul (2019), tacit knowledge awareness is 
the stage at which an individual realizes something new (e.g. an opinion or idea). At this stage, it can be shared. Therefore, the following hypothesis was developed:

H4. Tacit knowledge awareness positively influences tacit knowledge sharing.

\section{Tacit knowledge and innovations}

Tacit knowledge fosters innovations (Berraies et al., 2020; Goffin et al., 2010; Goffin and Koners, 2011; Jiménez-Jiménez and Sanz-Valle, 2011; Jisr and Maamari, 2017; Kodama, 2019; Pérez-Luño et al., 2016; Sakellariou et al., 2017; Sheng, 2019). As a result of tacit knowledge acquisition and recognition at the individual level, knowledge can be applied and shared at work and thanks to this shifted to communal level. Knowledge acquisition is a precondition for innovation (Rutten et al., 2016); if knowledge is not acquired, it cannot be shared. Moreover, Henri (2016) highlighted that knowledge sharing fosters idea generation among employees, which undoubtedly fosters innovation. Innovation can be perceived in several ways, but product versus process innovation is common (Eidizadeh et al., 2017; Jiménez-Jiménez and Sanz-Valle, 2011). The product or service innovation concept is wellestablished by many researchers, including Sheng (2019) and Ganguly et al. (2019), and it was operationalized by Kucharska and Erickson (2021). Product innovation relates to changes in an existing product or service in the aim of its development or the introduction of a new product or service. For clarity, this study refers to market-oriented external innovation, understood as product or service innovation and internal innovation, which refers to innovative methods of working. Process innovation, as the name suggests, develops operational management processes. Thus, tacit knowledge is a source of innovation (Brachos et al., 2006; Ganguly et al., 2019; Goffin et al., 2010; Goffin and Koners, 2011; Jisr and Maamari, 2017; Kodama, 2019; Pérez-Luño et al., 2019; Sakellariou et al., 2017; Sheng, 2019). Both service and product innovation, in contrast to internal-oriented innovations of aspects, such as processes, are market-oriented innovations. Therefore, for the purposes of this study, these innovations are referred to as market innovations. Besides, the innovative working methods may also inspire the external innovations of the product or service. These external innovations obtained thanks to internal often occur because of technological innovations (Donbesuur et al., 2020). So, it suggests that new solutions might inspire new ideas. As Crane and Bontis (2014, p. 1136) stated, "tacit knowledge is acquired unconsciously and automatically, but capable of influencing action." Based on this, the following hypotheses were formulated:

H5. Tacit knowledge awareness positively influences process innovation.

H6. Tacit knowledge awareness positively influences market innovation.

H7a. Tacit knowledge sharing fosters process innovations.

H8. Tacit knowledge sharing fosters market innovations.

Moreover, Hagedoorn and Wang (2012) suggested that complementarity exists between internal and external innovativeness, while Wong and Chin (2007) and Jiménez-Jiménez et al. (2008) noted that internal process innovations might increase overall innovativeness. Therefore, it is assumed that internal innovations may significantly support external, marketoriented product or service innovations. Thus, the following hypothesis was proposed:

H9. Process innovations positively influence market innovations.

\section{Control variables}

A control variable (CV) represents an additional factor (third variable) that may influence the relationship between an independent and dependent variable. A CV may act as a confound, a moderator or a suppressor (MacKinnon et al., 2000; Spector and Brannick, 2011). The CV's imputation methodology enables extraneous variables to be included in a 
model - they are not the focal point of the study, yet remain theoretically important (Becker et al., 2016; Kish, 1959; Nielsen and Raswant, 2018). For this study, such theoretically important variables were risk and critical thinking. Tacit knowledge is highly personal; thus, for this knowledge to arise, reflexivity is needed. All experience gained must be facilitated by critical thinking to create new knowledge (Oswald and Mascarenhas, 2019). Moreover, knowledge sharing, especially tacit knowledge, may also depend on risk-taking readiness. Risk taking implies uncertainty acceptance (Zinn, 2020). Tacit knowledge is novel, sometimes not fully developed, and just newly learned; thus, implementing such new learning in practice can require a certain degree of risk. Sharing, externalizing and implementing novel knowledge must be undertaken by somebody, mentally ready to be wrong - this person must feel comfortable and safe in facing uncertainty and risk in front of others (Andersson et al., 2020). Therefore, the general risk-taking attitude toward internal innovation introduction was included in this study as a CV. Based on all the above, the hypotheses were developed as follows:

CV1. Critical thinking positively influences tacit knowledge awareness.

CV2. Risk-taking attitude positively influences process innovation.

Based on all the above assumptions, the theoretical model was developed and is presented in Figure 1.

\section{Methodology}

\section{Questionnaire}

According to deVellis (2017, p. 2), "measurement is a fundamental activity of science." Social science measures focus on social constructs that are not easy to measure directly via, for example, observation. Hence, scales, which are collections of statements that reflect the meaning of a construct, are used to reveal unobserved social variables. Moreover, the methodological literature warns that measurement bias may occur by statement overlap (deVellis, 2017). Therefore, the current authors proposed their own scales, based on existing studies' findings and definitions, to ensure that the statements did not overlap and that the proposed model measured all constructs correctly to examine the above-described relations accurately and fulfill the study objectives. In summary, the first statements were developed according to given definitions from prior qualitative studies' findings, and then these scales were validated according to procedures described by deVellis (2017). Table 1

\section{Figure 1 Theoretical model}

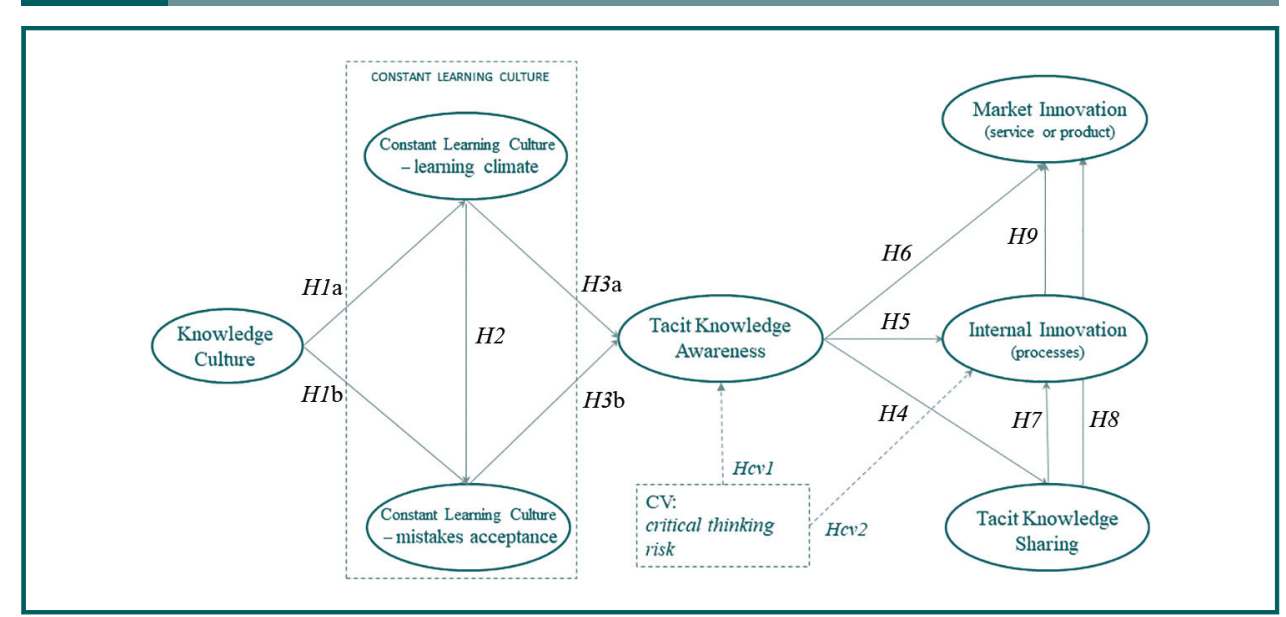

VOL. 25 NO. 112021 JOURNAL OF KNOWLEDGE MANAGEMENT $\mid$ PAGE 111 


\begin{tabular}{|c|c|c|}
\hline Construct & Meaning & Statements \\
\hline $\begin{array}{l}\text { Knowledge } \\
\text { culture }\end{array}$ & $\begin{array}{l}\text { Knowledge culture is consisted of all surrounding conditions } \\
\text { that support the effective and efficient flow of knowledge } \\
\text { throughout the whole organization } \\
\text { (Islam et al., 2013, 2015) }\end{array}$ & $\begin{array}{l}\text { All employees perceive knowledge as a value } \\
\text { We have a common language to support knowledge exchange } \\
\text { We are encouraged to share knowledge, ideas and thoughts } \\
\text { We care about quality of knowledge we share } \\
\text { (Kucharska and Bedford, 2020) }\end{array}$ \\
\hline Learning culture & $\begin{array}{l}\text { "(...) learning as one of the organization's core values, a focus } \\
\text { on people, concern for all stakeholders, stimulation of } \\
\text { experimentation, encouraging an attitude of responsible risk, } \\
\text { readiness to recognize errors and learn from them, and } \\
\text { promotion of open and intense communication, as well as the } \\
\text { promotion of cooperation, interdependence, and share of } \\
\text { knowledge" } \\
\text { (Rebelo and Gomes, } 2011 \mathrm{a}, \text { p. 174) } \\
\text { Hence, organizational constant learning culture is composed of } \\
\text { "learning climate" and "mistakes acceptance." }\end{array}$ & $\begin{array}{l}\text { "Learning climate" dimension: } \\
\text { We are encouraged to personal development } \\
\text { We are encouraged to implement new ideas every day } \\
\text { We are encouraged to new solutions seeking } \\
\text { "Mistakes acceptance" dimension: } \\
\text { People know that mistakes are learning consequence and } \\
\text { tolerate it up to a certain limit } \\
\text { Most people freely declare mistakes } \\
\text { We discuss problems openly without blaming } \\
\text { Mistakes are tolerated and treated as learning opportunities } \\
\text { (Kucharska and Bedford, 2020) }\end{array}$ \\
\hline Critical thinking & $\begin{array}{l}\text { "Critical thinking (CT) is constructive thinking about the world of } \\
\text { ours that questions and evaluates its operations, history, and } \\
\text { management" } \\
\text { (Oswald and Mascarenhas, } 2019, \text { p. 151) }\end{array}$ & $\begin{array}{l}\text { Making sense of things is important to me } \\
\text { I learn from constructive questioning } \\
\text { I like to evaluate my work and find out better solutions on my own } \\
\text { (Kucharska and Erickson, 2021) }\end{array}$ \\
\hline $\begin{array}{l}\text { Tacit knowledge } \\
\text { awareness }\end{array}$ & $\begin{array}{l}\text { Tacit knowledge is a common outcome from many episodes of } \\
\text { non-formal learning. It is often a reactive, situational near- } \\
\text { spontaneous and unplanned process. The learner is usually } \\
\text { aware of it, but the articulation of its effects in explicit form is } \\
\text { delicate without setting aside time for more refection and thus } \\
\text { becoming deliberative } \\
\text { (Eraut, 2000) }\end{array}$ & $\begin{array}{l}\text { I can create and explain new ideas or insights } \\
\text { Even if my idea is hard to explain, I am able to express it or } \\
\text { demonstrate it } \\
\text { Sometimes I am absolutely sure about a new idea but find it } \\
\text { difficult to express } \\
\text { As I have accumulated experience, I find it is easier to express } \\
\text { (Kucharska and Erickson, 2021) }\end{array}$ \\
\hline $\begin{array}{l}\text { Tacit knowledge } \\
\text { sharing }\end{array}$ & $\begin{array}{l}\text { Tacit knowledge sharing is a voluntary, social process. Sharing } \\
\text { informal knowledge is an informal voluntary act of the knowledge } \\
\text { owner } \\
\text { (Kucharska and Kowalczyk, 2016) } \\
\text { The tacit knowledge is obtained and shared through experience } \\
\text { (Göksel and Aydintan, 2017) }\end{array}$ & $\begin{array}{l}\text { I share knowledge learned from my own experience } \\
\text { I have the opportunity to learn from others' experiences } \\
\text { Colleagues share new ideas with me } \\
\text { Colleagues include me in discussions about best practices } \\
\text { (Kucharska and Erickson, 2021) }\end{array}$ \\
\hline $\begin{array}{l}\text { Process } \\
\text { innovation }\end{array}$ & $\begin{array}{l}\text { Process innovation is an ability to constant improvement } \\
\text { methods of working } \\
\text { (Manu, 1992; Jiménez-Jiménez et al., 2008; Jiménez-Jiménez } \\
\text { and Sanz-Valle, 2011) }\end{array}$ & $\begin{array}{l}\text { We constantly improve the way we work } \\
\text { We are good at managing changes } \\
\text { We are highly disposed to introduce new methods and } \\
\text { procedures } \\
\text { We are highly disposed to accept new rules } \\
\text { (Kucharska and Erickson, 2021) }\end{array}$ \\
\hline $\begin{array}{l}\text { Product or service } \\
\text { innovation }\end{array}$ & $\begin{array}{l}\text { Product or service innovation is an ability to introduce a } \\
\text { competitive new product or service on the market } \\
\text { (Manu, 1992; Jiménez-Jiménez et al., 2008; Jiménez-Jiménez } \\
\text { and Sanz-Valle, 2011; Eidizadeh et al., 2017) }\end{array}$ & $\begin{array}{l}\text { We provide competitively superior innovations to our clients } \\
\text { Our innovations are perceived positively by our clients } \\
\text { We are better than competitors at introducing innovations } \\
\text { I am proud of our innovations } \\
\text { (Kucharska and Erickson, 2021) }\end{array}$ \\
\hline
\end{tabular}

presents a summary of this stage of the study - namely, the measured constructs and their definitions, and statements of the proposed measurement scales.

\section{Sampling}

The study's sensitivity and complexity required high-quality sampling procedures; however, given the population size (in Poland and the USA) and dispersion, simple random sampling would have been challenging. Therefore, panel-based quota sampling - with Poland's labor market structure as the reference (Statistics Poland, 2017) - provided the necessary randomness with reasonable efficiency. Sampling administration was provided online and executed by professional partners, Qualtrics (USA) and ASM (Poland). Survey execution took two months (January to February 2020). The questionnaire started with a short introduction that provided an overview of the study, including a definition of tacit knowledge. Next, a qualification question was asked to establish the respondents' minimum work experience and 
status as a "knowledge worker" in the IT industry. Respondents were also prompted with a short explanation of the meaning of "tacit knowledge" to ensure they understood what they were asked. The survey's core, excluding classification items, used a seven-point Likert scale to assess the intensity of statements. Data management was straightforward. Only fully completed questionnaires with SD $>0.4$ were included. Table 2 presents the sample structure.

The main difference between samples was the structure of company size. US companies were mostly represented by large companies, whereas Polish companies were mostly small- and medium-sized enterprises.

\section{Data quality}

The sample quality assessment started with invariance, then the Kaiser-Meyer-Olkin (KMO) measure of sampling adequacy and Harman one-factor tests. The samples came from two countries; thus, the invariance tests of adequacy were run first to verify if the measurement instrument operated properly across different populations. All scales were proposed by the authors, so required validation. Namely, this test measures if the questionnaire is nationally invariant - works properly in different populations. Thus, it verified if the questionnaire composed of the scales presented in Table 2 measured the constructs properly in both samples. To achieve this, multigroup confirmatory factor analysis (CFA) was applied (Byrne, 2016). For both samples included in the research size $n>300$, so the liberal alternative of models' global fit indices were applied - comparative fit index (CFI) and root mean square error of approximation (RMSEA) (Chen, 2007). The measured change $(\Delta)$ in model fits was about 0.01 or less for $\mathrm{CFI}$, and 0.015 or less for RMSEA; thus, the measurement model was nationally invariant (Byrne, 2016; Chen, 2007; Raudenska, 2020). Table 3 presents the

\section{Table 2 Sample structure}

$\begin{array}{lcc} & & \text { Poland } \\ \text { Respondents } & n=350 & \text { USA } \\ n=379\end{array}$

Table 3 Invariance measurement

MCFA models

Unconstrained model

Loading measurement equality - measurement model $(\Delta)$

Factor covariances equality - structural model $(\Delta)$

Notes: Poland, $n=350 ;$ USA, $n=379$ 
details of the invariance measurement, which indicate that the applied scales in the questionnaire created a nationally invariant tool. Table 3 presents the invariance measurement, while Table 4 presents the sample quality assessment.

Summarizing this stage, for all obtained KMO tests of the sample's adequacy, results were 0.872 for Poland and 0.927 for the USA, which confirmed that the samples were adequate (Hair et al., 2010; Kaiser, 1974). In addition, we ran one Harman single-factor test (Podsakoff and Organ, 1986), and both samples achieved an acceptable result, with 30\% for Poland and 39\% for the USA, which confirmed that the sample quality was good and enabled further analysis.

\section{Measures}

After positive verification of the sample and questionnaire quality, CFA was conducted to assess the convergent and discriminant validity of the empirical models run, separately for Poland and the USA, based on the theoretical model presented in Figure 1. The critical thinking $(C T)$ and risk (RISK) CVs were imputed. CT was operationalized as a composite variable from the seven-point Likert scale. The mean value of $C T$ was 6.45 (Poland/USA). Thus, the imputation of $C T$ as the $C V$ in the ordinal scale was the best option to measure the influence of $C T$ properly (differences between respondents were sensitive). RISK was measured and operationalized more simply ( $1=$ risk-taking person, $0=$ opposite). For Poland, the majority worked in small companies, and $78 \%$ of respondents described themselves as risk-taking people. The majority of the US sample comprised employees working in large companies, where $69 \%$ of respondents described themselves as risktaking people. All latent variables were measured using seven-point Likert scales. The other measured constructs achieved indicator loadings (standardized) above the reference level of >0.6 (Bartlett, 1950; Fornell and Larcker, 1981; Hair et al., 2010).

The internal consistency of the constructs was assessed using Cronbach's alpha $>0.7$ (Francis, 2001) and average variance extracted (AVE) > 0.5 (Byrne, 2016; Hair et al., 2010). Further, composite reliability $>0.7$ (Byrne, 2016; Hair et al., 2010) was used to justify the reliability of the scales. Next, after the positively assessed statistical power of the chosen items, discriminant validity was checked (deVellis, 2017; Fornell and Larcker, 1981; Hu and Bentler, 1999). Namely, similar theoretically related constructs were verified to ensure they did not supercharge each other (Fornell-Larcker criterion). The obtained square root of the AVE was larger than the correlation observed between the constructs for all except the process innovation $(P l)$ and market innovation $(P S I)$ variables in the US model, which meant that the discriminant validity of the proposed scales worked properly, except for this one case, which required deeper investigation. Therefore, Model C for the US sample was later run, analyzed and elaborated to further explain the relation between internal and external innovations in the IT industry in the USA. Table 5 presents the obtained basic statistics and correlations between the measured constructs.

The mean values for critical thinking, tacit knowledge awareness and knowledge culture were very close for Poland and the USA, while the mean values for process innovation and market innovations were slightly higher for the US sample. The mean values for learning climate and

Table 4 Samples quality

$\begin{array}{llc}\text { Samples } & \text { IT Poland } \\ n=350 & \text { IT } \\ \text { KMO } & & \begin{array}{c}\text { USA } \\ n=379\end{array} \\ \text { Harman one-factor test } & 30 \% & 0.927 \\ \text { Total variance explained } & 71 \% & 39 \% \\ \text { Common method variance } & 12 \% & 75 \% \\ \text { Notea: Poland, } n=350 ; \text { USA, } n=379 & & 22 \%\end{array}$


Table 5 Basic statistics, correlations, and root square of AVE

\begin{tabular}{|c|c|c|c|c|c|c|c|c|c|c|c|c|c|c|}
\hline & Mean & $S D$ & AVE & $C R$ & $\begin{array}{c}\text { Cronbach's } \\
\text { alpha }\end{array}$ & RISK & $C T$ & $K C$ & $\angle C A$ & $L C M$ & TKA & TKS & $P l$ & PSI \\
\hline \multicolumn{15}{|c|}{ Basic statistics, correlations and root square of AVE-Poland } \\
\hline CT & 6.23 & 0.79 & NA & NA & 0.708 & -0.059 & & & & & & & & \\
\hline KC & 6.14 & 0.097 & 0.56 & 0.79 & 0.729 & 0.008 & 0.263 & 0.745 & & & & & & \\
\hline LCA & 5.60 & 1.23 & 0.69 & 0.87 & 0.873 & 0.006 & 0.191 & 0.727 & 0.831 & & & & & \\
\hline LCM & 5.09 & 1.38 & 0.63 & 0.83 & 0.817 & 0.003 & 0.111 & 0.423 & 0.511 & 0.793 & & & & \\
\hline TKA & 6.12 & 0.90 & 0.50 & 0.75 & 0.758 & -0.015 & 0.353 & 0.327 & 0.402 & 0.195 & 0.705 & & & \\
\hline TKS & 5.90 & 1.07 & 0.53 & 0.76 & 0.735 & -0.021 & 0.138 & 0.127 & 0.156 & 0.076 & 0.388 & 0.728 & & \\
\hline $\mathrm{PI}$ & 5.45 & 1.18 & 0.58 & 0.81 & 0.801 & 0.069 & 0.093 & 0.09 & 0.111 & 0.054 & 0.274 & 0.308 & 0.764 & \\
\hline PSI & 5.81 & 1.02 & 0.61 & 0.82 & 0.814 & 0.045 & 0.102 & 0.097 & 0.12 & 0.058 & 0.296 & 0.252 & 0.71 & 0.778 \\
\hline \multicolumn{15}{|c|}{ Basic statistics, correlations and root square of AVE-USA } \\
\hline & Mean & $S D$ & AVE & $C R$ & $\begin{array}{c}\text { Cronbach's } \\
\text { alpha }\end{array}$ & RISK & $C T$ & $K C$ & $\angle C A$ & LCM & TKA & TKS & $P I$ & PSI \\
\hline CT & 6.45 & 0.87 & NA & NA & 0.731 & 0.142 & & & & & & & & \\
\hline $\mathrm{KC}$ & 6.11 & 1.00 & 0.59 & 0.81 & 0.828 & 0.237 & 0.417 & 0.770 & & & & & & \\
\hline LCA & 6.04 & 0.97 & 0.57 & 0.80 & 0.773 & 0.177 & 0.312 & 0.747 & 0.753 & & & & & \\
\hline LCM & 5.76 & 1.26 & 0.60 & 0.82 & 0.838 & 0.171 & 0.302 & 0.723 & 0.743 & 0.772 & & & & \\
\hline TKA & 6.11 & 1.06 & 0.63 & 0.84 & 0.854 & 0.166 & 0.475 & 0.384 & 0.366 & 0.393 & 0.794 & & & \\
\hline TKS & 6.19 & 0.96 & 0.54 & 0.78 & 0.793 & 0.127 & 0.33 & 0.268 & 0.255 & 0.273 & 0.693 & 0.733 & & \\
\hline $\mathrm{PI}$ & 5.83 & 1.15 & 0.59 & 0.81 & 0.832 & 0.371 & 0.156 & 0.167 & 0.143 & 0.147 & 0.285 & 0.384 & 0.768 & \\
\hline PSI & 5,96 & 1.16 & 0.64 & 0.84 & 0.836 & 0.355 & 0.208 & 0.204 & 0.18 & 0.188 & 0.398 & 0.443 & 0.935 & 0.798 \\
\hline
\end{tabular}

mistakes acceptance - the learning culture variables - were lower for the Polish sample. Therefore, learning culture, tacit knowledge sharing and internal and external innovations were areas where differences between Poland and the USA were expected (Figure 1).

\section{Results}

The results obtained for Poland and the USA are presented based on two models: Model A - run with CVs, and Model B - run without CVs (Aguinis and Vandenberg, 2014; Carlson and $\mathrm{Wu}, 2012$ ). The results of both models are presented following the procedure suggested by Becker et al. (2016) in Table 6. Based on these results, the conclusion was reached that Model B with imputed CVs fit the data better for both samples - Polish and American. Thus, further analysis based on Model B with CVs was undertaken and discussed. Additionally, for the American sample, Model C without the PSI (external innovations) variable was analyzed, as the Fornell-Larcker criterion was not fulfilled for the American sample in Model B, yet the common method bias and Harman one-factor tests achieve acceptable levels (Table 4) - none of the results exceeded 50\% (Fuller et al., 2016; Podsakoff et al., 2012). Therefore, Model $\mathrm{C}$ was created to verify if $P S /$ variable inclusion in the model was justified. Namely, if PI (internal innovations) supercharged PSI (external, market innovations), then it may be better to exclude this variable. The results obtained for Model C demonstrated that inclusion of both variables - PI (process innovation) and PSI (market innovations) - was necessary to fully understand the whole mechanism of learning via mistakes to develop innovativeness in IT organizations. PSI inclusion was justified because Model B (with both $P I$ and $P S /$ variables) obtained $R^{2}=89 \%$, whereas, without $P S I$, it obtained only $24 \%$. Altogether, this indicated that the $P S /$ variable should be included and analyzed for better understanding the whole explored mechanism of relations. Based on the presented results, it may be theorized that the IT industry in the USA is simply innovation oriented, and all internal innovations are focused on market innovations delivery ( $\beta=$ $\left.0.87^{* * *}\right)$. Moreover, Model B fitted better to the data than Model C. Therefore, the 
Table 6 Hypothesis verification details

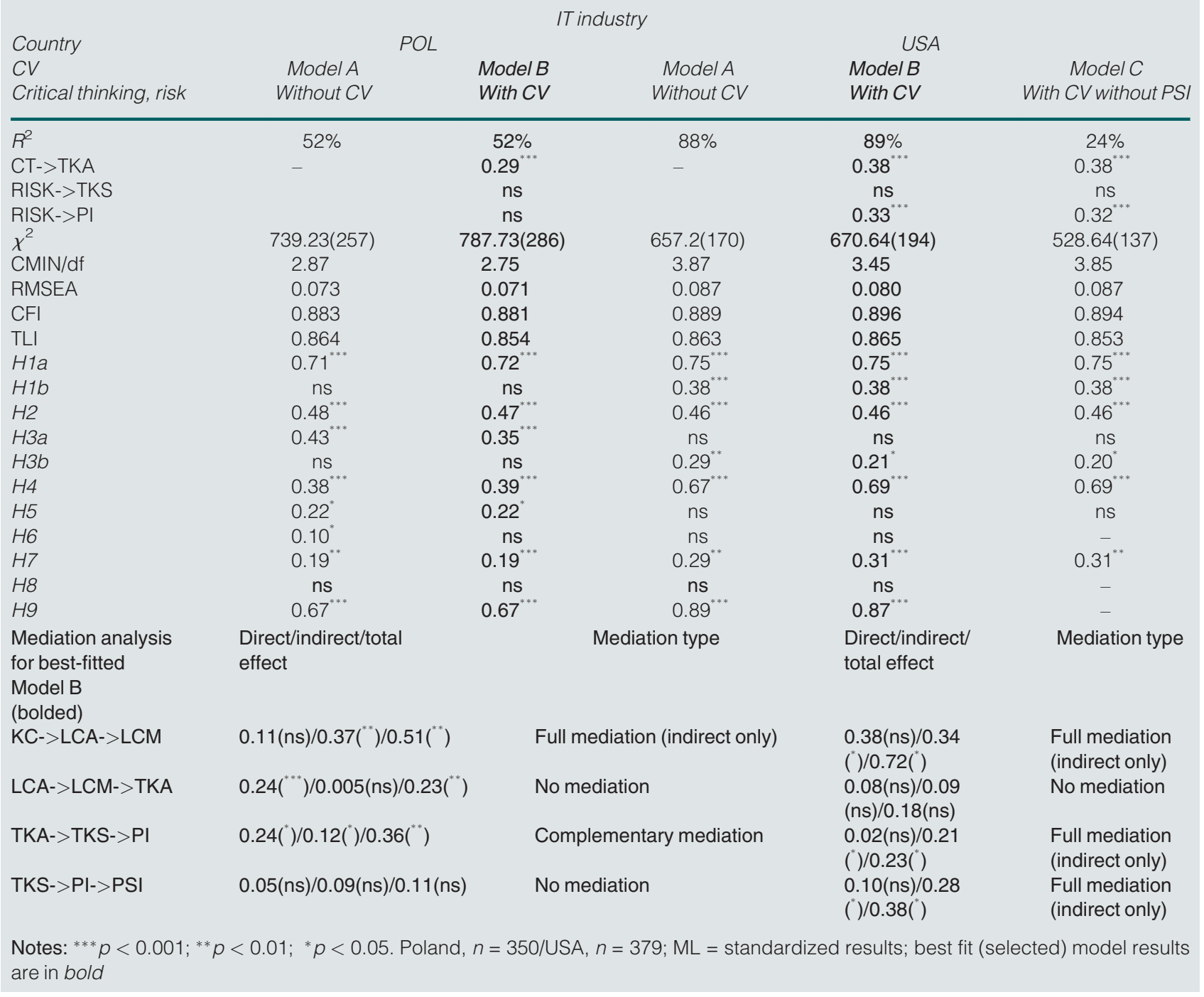

conclusion was reached that the American IT industry is greatly consistently innovation oriented. This conclusion is supported by the fact that PI supercharges PSI (Table 5b). However, if the PSI variable is excluded (Table 6, Model C), the model quality decreases, as described above. Thus, it means that internal innovations in the US IT companies strongly support external innovations. Moreover, the influence of tacit knowledge sharing on market innovations is fully supported by internal innovations.

Thus, the internal processes of IT companies (represented in 66\% by large companies) are market innovation oriented, whereas in Poland (represented in $77 \%$ by small companies), they are not. This is a particularly important discovery worth discussing in greater depth, especially in the context of the full results obtained based on hypotheses verification (Table 6). Figure 2 presents graphically all the obtained results based on Model B with CVs.

This study aimed to understand and compare how the mechanism of innovative processes in the IT industry is shaped in Poland and the USA in terms of tacit knowledge awareness and sharing driven by mistakes acceptance. There was no other way to undertake this investigation in detail with a simple model. Therefore, the presented model comprises seven latent variables linked by 11 hypotheses to ensure that the whole mechanism was simulated 


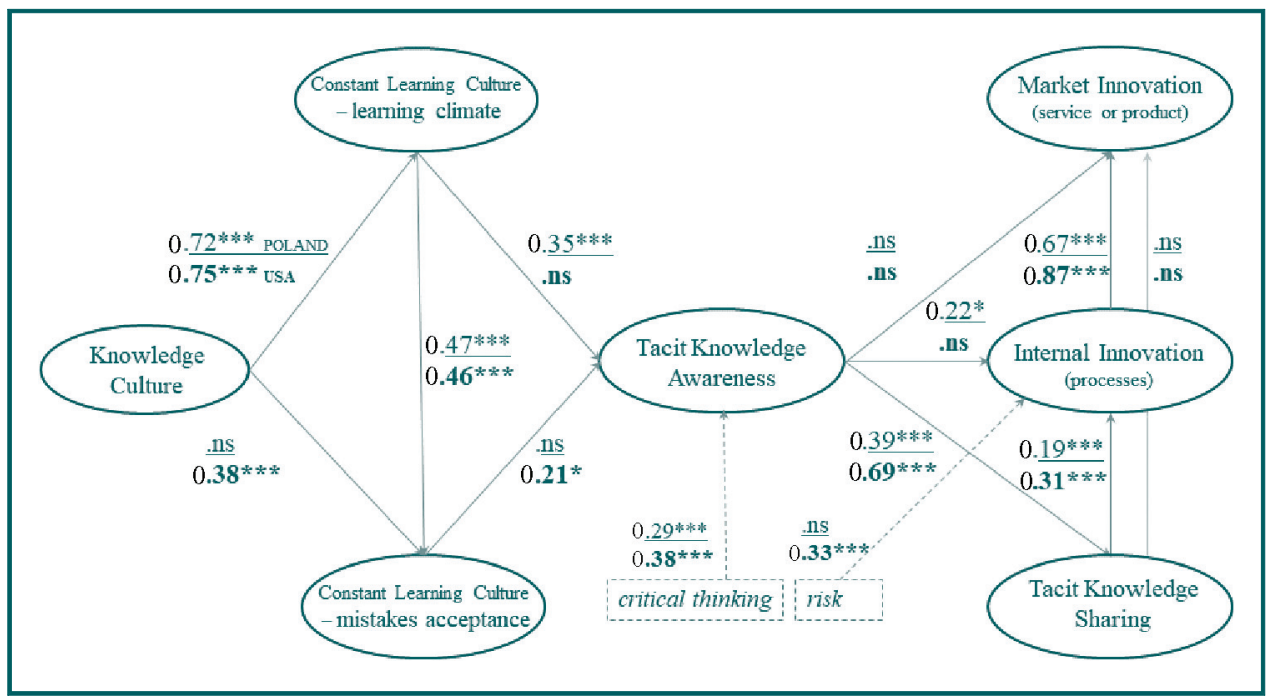

and ensure two critical CVs were imputed and the indirect (mediated) effects were analyzed. So, elaborating the model quality issues, it is methodologically correct if such complex model obtain slightly lower than referenced by Bentler (1990) $0.9 \mathrm{CFI}$ and referenced TLI also 0.9 (Tucker and Lewis, 1973) levels if only RMSEA and CMIN/df are correct (Cheung and Rensvold, 2009). Exactly this situation was observed in the case of the present study. This study was complex because the study aim required it - namely, detailed modeling was required to understand the mechanism of learning from mistakes to increase innovativeness via tacit knowledge awareness and sharing. Simplification by reducing degrees of freedom would somewhat improve the quality of the model, but the delivery of the knowledge in which we were interested would be at risk. Table 6 and Figure 2 visualize the obtained results.

The $R^{2}$ of the model developed based on the Polish IT sample obtained $52 \%$. This result indicates that other important factors influence the market innovativeness of Polish companies that were not included in this research. The $R^{2}$ obtained was $89 \%$ for the US IT sector, which was perceived as impressive and the obtained results could thus be discussed as endorsed.

\section{Discussion}

The presented study results exposed several issues. Starting from knowledge culture, the influence of it on learning culture is equally observed for Poland and the USA, but only in terms of learning climate (H1a). When considering the mistakes acceptance component, for Poland, this influence was not significant, whereas, for the USA, the result was the opposite (H1b). This means that, in Poland, there exists some kind of "learning illusion" - namely, employees are expected to learn without making mistakes. This finding aligns with Kucharska and Bedford's (2020) findings. They observed that Polish employee intelligence increases by learning from mistakes, whereas organization's intelligence is not. For the US sample, mistakes acceptance significantly influenced tacit knowledge awareness (H3b), whereas, for the Polish sample, it did not. Inversely, the learning climate positively influenced tacit knowledge awareness for Poland, yet was not significant for the USA. Thus, this situation is a result of knowledge culture, which, in Poland, supports learning climate (H1a), yet ignores mistake acceptance (H1b). For the US sample, both learning culture components - mistakes acceptance and learning climate - were fostered by knowledge 
culture. However, the direct and indirect (mediated) effects of the learning climate on tacit knowledge awareness were both not significant. This means that, for IT in the USA, the mistakes acceptance factor of the learning culture is a focal stimulus for tacit knowledge awareness. This finding aligns with Örtenblad (2002) that a learning climate encourages learning through trials, experiments and errors, and enhances reflections. Developing these thoughts, Srirama et al. (2020) examined the IT sector in India, and noted that it is important to allow employees to experiment, explore and debate. To achieve true learning, organizations must create a working environment where people can discuss without hesitation, and employees must be able to accept critical feedback and questioning. This highlights the second important issue noted in this study - that true learning derives from mistakes acceptance. According to Senge's (2006) statement, to truly learn, we must be ready to be wrong. This study demonstrates this empirically. Moreover, learning climate mediates between knowledge culture and mistakes acceptance, as observed for both Poland and the USA. This means that learning climate is an important facilitator for learning from mistakes.

The next tremendous difference between models worth to be discussed is tacit knowledge awareness influence on internal and external innovations. Tacit knowledge awareness is the moment when we start to realize something new, so we have learned something. As Crane and Bontis (2014, p. 1136) stated, tacit knowledge is on its early stage "acquired unconsciously and automatically, but capable of influencing action." This statement was supported by the current study's findings. However, although the direct influence of tacit knowledge awareness on external innovations (H6) was not significant, and on internal was significant only for Poland; this influence was mediated by tacit knowledge sharing. Namely, tacit knowledge awareness influence on market innovations was fully mediated by internal innovations. In contrast, for Poland, mediation is noted for internal innovations, and the direct effect of tacit knowledge awareness on P/ was significant (H5), and the mediation of internal innovations was partial. Further, for the USA, tacit knowledge sharing (H4) was crucial for innovativeness (internal and external). Process innovation directly influenced market innovation and was high and significant for both samples; however, the US internal innovativeness in the IT industry strongly supports market innovativeness. As noted in the results section describing the high correlation between $P S /$ and $P I$ for the US sample, and in the poor results of Model $\mathrm{C}$ - which was run only to test what would occur with the whole model when PSI was excluded - Model C was much weaker than Model B, where, despite the high correlation between $\mathrm{PI}$ and $P S I$, bias was not observed. Altogether, these results indicate that the IT industry in the USA is completely innovation oriented, and all internal innovations are focused on improving methods of working to create better external innovations. Notably, the direct influence of tacit knowledge sharing on market innovation was not significant $(H 8)$, but the indirect effect was significant. Further, the impact of TKS on $P S /$ was fully mediated by $P I$ (internal innovations). All these results suggest that there is a remarkable internal innovation mindset in the US IT industry that affects externally oriented innovativeness (market innovations). This is important empirical evidence delivered by this research - namely, that true learning leads to innovativeness consistency of organizations, as evident in internal and external innovativeness.

More light on this situation put an analysis of CVs: critical thinking and risk. Both CVs were significant for the US sample - namely, critical thinking mattered for tacit knowledge awareness and risk-taking attitude mattered for process innovations. For the Polish sample, risk was not a significant influencer, whereas critical thinking was (Table 5). This finding was interesting. As Zinn (2020) stated, risk taking implies uncertainty acceptance. Tacit knowledge is novel, sometimes not fully developed, and just newly learned, so implementing such new learning in practice includes a certain degree of uncertainty, such as the risk of mistake. Therefore, for the Polish sample, where mistakes are not accepted, employees do not take the risk, and their innovativeness is not as strong as in the USA. Another issue worth discussion is the fact that the Polish sample comprised a majority of 
small company entrepreneurs who declared themselves risk-taking people, and the average level of the critical thinking factor in the Polish sample was also high. This means that the lack of mistakes acceptance affects the learning process, thereby influencing tacit knowledge awareness much more intensively in Poland than in the USA. To enable a better understanding of these theorized interrelations, Figure 3 presents a visualization of tacit knowledge awareness, mistakes acceptance, risk taking and critical thinking. This visualization is presented for the US sample because all these factors were significant only for the USA.

Figure 3 presents that employees with the strongest critical thinking obtained the highest level of tacit knowledge awareness in the group of risk-taking employees, which correlated with the highest level of mistakes acceptance. Based on this visualization, the conclusion reached was that a high level of mistakes acceptance stimulated by a risk-taking attitude generates a high level of tacit knowledge awareness because of critical thinking. The same strong level of critical thinking without a risk-taking attitude generates a stable level of tacit knowledge awareness, even when mistakes acceptance is high. This suggests that risktaking attitude is only partially shaped by working conditions. The best example of this is that "critical thinkers" on the higher level, who are not risk-taking people, obtain a lower level of tacit knowledge awareness than those whose critical thinking is not as high but are ready to take a risk. Namely, the inner criticism of persons who cannot take a risk kills new ideas. So, critical thinking without readiness to take a risk is not good for tacit knowledge capturing. All the above findings lead to interesting practical and scientific implications.

\section{Implications and limitations}

Tacit knowledge is personal, and this study indicates that organizational culture might significantly stimulate tacit knowledge, yet the personality of the employee is shaped by their home culture - for example, family, friends, former experiences and national culture may also influence readiness to gain tacit knowledge and implement it in action. Both samples were represented by knowledge workers, so personal, intellectual disposition was not the issue of this study. The essence was the individual and communal attitude shaped

\section{Figure 3 Mistakes acceptance and tacit knowledge awareness in terms of critical thinking} and risk-taking conditions - the US case

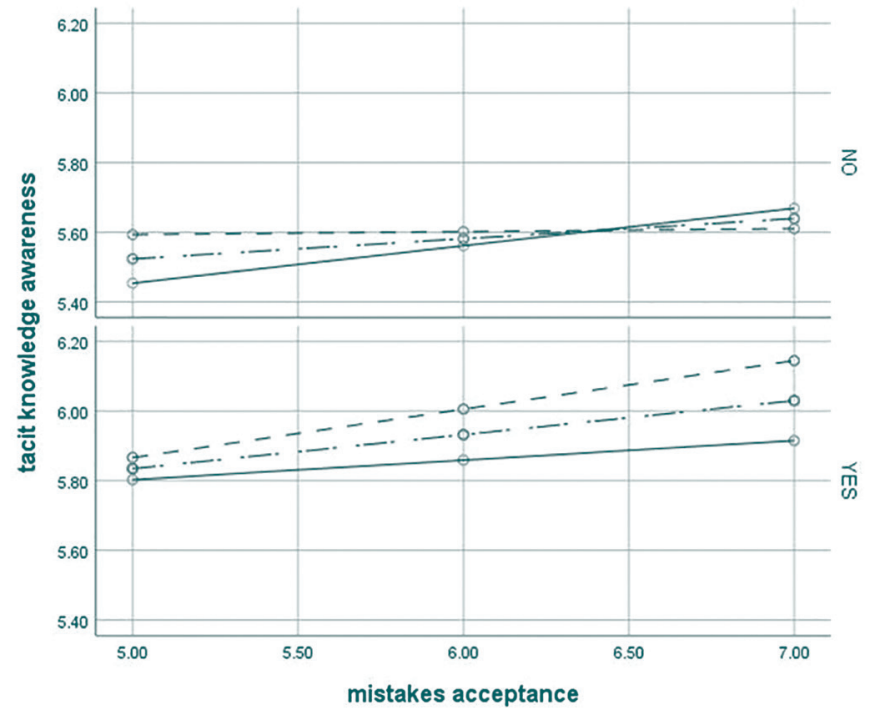


by culture - organizational and national (Bedford and Kucharska, 2020). This national culture influence may also explain why Polish employees' attitudes toward mistakes acceptance and risk taking are so negative and so opposite to those presented by the US IT knowledge workers. Poland is a post-soviet country who, after harmful the Second World War experiences, lived more than 50 years in fear. Such harmful events can affect many generations. It is an interesting topic for sociologists to investigate how deeply and how long such hidden fear can be transferred at unconscious levels through generations. Therefore, it is worth examining other post-soviet countries. Does their national experience affect the way tacit knowledge is created, shared and generally managed? Does it differentiate across industries? Which factors influence tacit knowledge sharing in large and small companies? The obtained differences observed in this study between the USA and Poland may also be caused by company size factor. These questions require further research.

Practical implications based on the presented findings are clear. The illusion of learning without making mistakes causes a kind of organizational waste, reflected in the lost opportunity to learn. True learning comes from mistake acceptance, as empirically demonstrated by this study. Thus, organizations should develop a culture and rules to support learning from mistakes. If a true learning culture leads to remarkable "consistent innovativeness," both internal and external. Therefore, the organizational effort needed to support learning from mistakes is worth investing in. If a company can support learning from mistakes by developing an appropriate culture and selecting suitable leaders, then the chance for tacit knowledge capturing and sharing grows. Another important factor is hiring suitable people - not only leaders but generally, all knowledge workers, who think critically and take risks of the uncertainty of new ideas formulation. If not, the organizational effort to organize the learning process may be lost.

The main limitation of this study is that it provided a comparison between two countries (including one of the most innovative globally) and one industry (also the most innovative globally). Thus, further studies exploring other countries and industries would be beneficial to learn more about the "mistake acceptance" phenomenon around the world. It would be useful to include other Asian and European countries in future studies, including other postsoviet countries. National cultural context matters for organizational studies including cultural factor. This fact can determine that the same phenomenon can be perceived differently considering national cultures lens. Moreover, the difference between the Polish and US sample regarding company size may have affected the identified differences. This limitation should be considered when analyzing and applying the knowledge from this study. This is a good starting point for further research about tacit knowledge awareness and the sharing of small and large companies' differences. Moreover, in this study, "mistake acceptance" is perceived as a proxy for learning from mistakes. Indeed, learning is not possible if the source of learning is not accepted. Still, the obtained $R^{2}=52 \%$ (Poland) suggests that some other variables are not included in this study but might be significant for the better understanding of gathering tacit knowledge from mistakes for Poland. For the USA $\left(R^{2}=89 \%\right)$, the applied proxy seems to be quite accurate. This fact justifies further cross-country studies. Different factors might be focal to explain the phenomenon in national cultures. So, knowing them enables us to broaden the body of knowledge.

A new, exciting direction for further studies on organizational behavior naturally emerges based on the presented findings. That is, it is particularly important to identify all factors that may influence learning from mistakes, other than the abovementioned factors of supportive leadership and authentic learning culture, which are undoubtedly crucial. A question arises: "How exactly should rules to support learning from mistakes be created?" Learning from mistakes requires deep reflexivity as well as a climate of psychological safety that comforts the individual (Edmondson and Verdin, 2018; Frazier et al., 2017; Kurtessis et al., 2017). This study is based on knowledge workers - a skilled group of employees - but even for such 
groups, important factors, such as personal motivation, an open-minded attitude or the general capability of the particular individual to learn, may affect individuals' ability to learn from mistakes. In addition, Parker et al. (2020) noted that organizational reflexivity is not exclusively the individual's action - it is a co-created corporate practice within a specific organizational context. Therefore, it is essential to identify factors that support organizational learning from mistakes in different contexts. This proposed research direction is vital to organizational development and hence requires more in-depth qualitative and quantitative studies.

\section{Conclusion}

This study aimed to understand and compare how the mechanism of innovative processes in the IT industry - the most innovative industry worldwide - is shaped in Poland and the USA in terms of tacit knowledge awareness and sharing driven by a culture of knowledge and learning, composed of learning climate and mistake acceptance. Empirical research based on the IT industry in Poland and the USA was analyzed using the structural equation modeling method. As a result of a risk-taking attitude and critical thinking, the IT industry in the USA is consistently innovation oriented. Specifically, external innovations are highly correlated with internal innovations. It was empirically demonstrated based on a true learning culture composed of learning climate and mistake acceptance. Moreover, the learning climate is an important facilitator for learning from mistakes. The novelty of the presented findings can be summed up by stating that this research delivered empirical proof that a high level of mistake acceptance stimulates a risk-taking attitude that provides a high level of tacit knowledge awareness due to critical thinking. Thus, this study revealed that true learning derives from mistake acceptance.

\section{References}

Abubakre, M., Zhou, Y. and Zhou, Z. (2020), "The impact of information technology culture and personal innovativeness in information technology on digital entrepreneurship success", Information Technology \& People, doi: 10.1108/ITP-01-2020-0002.

Aguinis, H. and Vandenberg, R.J. (2014), "An ounce of prevention is worth a pound of cure: improving research quality before data collection”, Annual Review of Organizational Psychology and Organizational Behavior, Vol. 1 No. 1, pp. 569-595.

Akinsola, J.E.T., Ogunbanwo, A.S., Okesola, O.J., Odun-Ayo, I.J., Ayegbusi, F.D. and Adebiyi, A.A. (2020), "Comparative analysis of software development life cycle models (SDLC)", in: Silhavy R. (Ed.) Intelligent Algorithms in Software Engineering. CSOC 2020. Advances in Intelligent Systems and Computing, Vol. 1224, Springer, Cham, doi: 10.1007/978-3-030-51965-0_27.

Anderson, J.G. and Abrahamson, K. (2017), "Your health care may kill you: medical errors", Studies in Health Technology and Informatics, Vol. 234, pp. 13-17.

Andersson, M., Moen, O. and Brett, P.O. (2020), "The organizational climate for psychological safety: associations with SMEs' innovation capabilities and innovation performance", Journal of Engineering and Technology Management, Vol. 55, p. 101554, doi: 10.1016/j.jengtecman.2020.101554.

Annosi, M.C., Martini, A., Brunetta, F. and Marchegiani, L. (2020), "Learning in an agile setting: a multilevel research study on the evolution of organizational routines", Journal of Business Research, Vol. 110, pp. 554-566.

Anu, V., Hu, W., Carver, J.C., Walia, G.S. and Bradshaw, G. (2018), "Development of a human error taxonomy for software requirements: a systematic literature review", Information and Software Technology, Vol. 103, pp. 112-124.

Asher, D. and Popper, M. (2019), "Tacit knowledge as a multilayer phenomenon: the 'onion' model”, The Learning Organization, Vol. 26 No. 3, pp. 264-275, doi: 10.1108/TLO-06-2018-0105.

Balaji, S. and Murugaiyan, M.S. (2012), "Waterfall vs V-model vs agile: a comparative study on SDLC", International Journal of Information Technology and Business Management, Vol. 2 No. 1, pp. 26-30. 
Bartlett, M.S. (1950), "Tests of significance in factor analysis", British Journal of Statistical Psychology, Vol. 3 No. 2, pp. 77-85.

Becker, T.E., Atnic, G., Breaugh, J.A., Carlson, K.D., Edwards, J.R. and Spector, P.E. (2016), "Statistical control in correlational studies: 10 essential recommendations for organizational researchers", Journal of Organizational Behavior, Vol. 37 No. 2, pp. 157-167.

Bedford, D.A.D. and Kucharska, W. (2020), Relating Information Culture to Information Policies and Management Strategies, IGI Global.

Bentler, P.M. (1990), "Comparative fit indexes in structural models", Psychological Bulletin, Vol. 107 No. 2, pp. 238-246.

Berraies, S., Hamza, K.A. and Chtioui, R. (2020), "Distributed leadership and exploratory and exploitative innovations: mediating roles of tacit and explicit knowledge sharing and organizational trust", Journal of Knowledge Management, doi: 10.1108/JKM-04-2020-0311.

Björkdahl, J. and Börjesson, S. (2012), "Assessing firm capabilities for innovation", International Journal of Knowledge Management Studies, Vol. 5 Nos 1/2, pp. 171-184.

Bligh, J., Kohles, C. and Yan, Q. (2018), "Leading and learning change", Journal of Change Management, Vol. 18 No. 2, pp. 116-141, doi: 10.1080/14697017.2018.1446693.

Bourdeau, S., Aubert, B. and Bareil, C. (2020), "The effects of IT use intensity and innovation culture on organizational performance: the mediating role of innovation intensity", Management Research Review, Vol. 44 No. 2, doi: 10.1108/MRR-02-2020-0068.

Brachos, D., Kostopolous, K., Soderquist, K.E. and Prastacos, G. (2006), "Knowledge effectiveness, social context and innovation", Journal of Knowledge Management, Vol. 11 No. 5, pp. 31-44, doi: 10.1108/13673270710819780.

Byrne, B.M. (2016), Structural Equation Modeling with Amos, Routledge, Abingdon.

Cabrilo, S., Dahms, S., Burgos Mutuc, E. and Marlin, J. (2020), "The role of IT practices in facilitating relational and trust capital for superior innovation performance: the case of Taiwanese companies", Journal of Intellectual Capital, Vol. 21 No. 5, pp. 753-779.

Cabrilo, S., Kianto, A. and Milic, B. (2018), "The effect of IC components on innovation performance in Serbian companies", VINE Journal of Information and Knowledge Management Systems, Vol. 48 No. 3 , pp. 448-466, doi: 10.1108/NJIKMS-06-2016-0033.

Cannon, M.D. and Edmondson, A.C. (2001), "Confronting failure: antecedents and consequences of shared beliefs about failure in organizational work groups", Journal of Organizational Behavior, Vol. 22 No. 2, pp. 161-177.

Cardon, M.S., Stevens, C.E. and Potter, D.R. (2011), "Misfortunes or mistakes?: cultural sensemaking of entrepreneurial failure", Journal of Business Venturing, Vol. 26 No. 1, pp. 79-92.

Carlson, K.D. and Wu, J. (2012), "The illusion of statistical control: control variable practice in management research", Organizational Research Methods, Vol. 15 No. 3, pp. 413-435.

Challa, H., Niu, N. and Johnson, R. (2020), "Faulty requirements made valuable: on the role of data quality in deep learning", 2020 IEEE Seventh International Workshop on Artificial Intelligence for Requirements Engineering (AIRE). 10.1109/AIRE51212.2020.00016.

Chen, F.F. (2007), "Sensitivity of goodness of fit indexes to lack of measurement invariance", Structural Equation Modeling: A Multidisciplinary Journal, Vol. 14 No. 3, pp. 464-504, doi: 10.1080/ 10705510701301834.

Cheung, G.W. and Rensvold, R.B. (2009), "Evaluating goodness-of-fit indexes for testing measurement invariance", Structural Equation Modeling: A Multidisciplinary Journal, Vol. 9 No. 2, pp. 233-255, doi: 10.1207/S15328007SEM0902_5

Choi, T. and Chandler, S.M. (2020), "Knowledge vacuum: an organizational learning dynamic of how egovernment innovations fail”, Government Information Quarterly, Vol. 37 No. 1, p. 101416.

Cope, J. (2011), "Entrepreneurial learning from failure: an interpretative phenomenological analysis", Journal of Business Venturing, Vol. 26 No. 6, pp. 604-623.

Crane, L. and Bontis, N. (2014), "Trouble with tacit: developing a new perspective and approach", Journal of Knowledge Management, Vol. 18 No. 6, pp. 1127-1140. 
De Felice, F. and Petrillo, A. (2017), Theory and Application on Cognitive Factors and Risk Management New Trends and Procedures, IntechOpen, London.

Denning, S. (2013), "Why agile can be a game changer for managing continuous innovation in many industries", Strategy \& Leadership, Vol. 41 No. 2, pp. 5-11, doi: 10.1108/10878571311318187.

deVellis, R.F. (2017), Scale Development: Theory and Applications, Sage, Thousand Oaks.

Di Sanzo, P., Avresky, D.R. and Pellegrini, A. (2021), "Autonomic rejuvenation of cloud applications as a countermeasure to software anomalies", Software: Practice and Experience, Vol. 51 No. 1, pp. 46-71.

Donbesuur, F., Ampong, G.O.A., Owusu-Yirenkyi, D. and Chu, I. (2020), "Technological innovation, organizational innovation and international performance of SMEs: the moderating role of domestic institutional environment", Technological Forecasting and Social Change, Vol. 161, p. 120252.

Dörfler, V. and Ackermann, F. (2015), "Understanding intuition: the case for two forms of intuition", Management Learning, Vol. 43 No. 5, pp. 545-564, doi: 10.1177/1350507611434686.

Edmondson, A.C. and Verdin, P.J. (2018), "The strategic imperative of psychological safety and organizational error management”, How Could This Happen?, Palgrave Macmillan, Cham, pp. 81-104.

Eggers, J.P. and Song, L. (2015), "Dealing with failure: serial entrepreneurs and the costs of changing industries between ventures", Academy of Management Journal, Vol. 58 No. 6, pp. 1785-1803.

Eidizadeh, R., Salehzadeh, R. and Esfahami, A.C. (2017), "Analysing the role of business intelligence. knowledge sharing and organizational innovation on gaining competitive advantage", Journal of Workplace Learning, Vol. 29 No. 4, pp. 250-267.

El-Den, J. and Sriratanaviriyakul, N. (2019), "The role of opinions and ideas as types of tacit knowledge", Procedia Computer Science, Vol. 161, pp. 23-31.

Eraut, M. (2000), "Non-formal learning and tacit knowledge in professional work", British Journal of Educational Psychology, Vol. 70, pp. 113-136, doi: 10.1348/000709900158001.

Fan, P., Urs, N. and Hamlin, R.E. (2019), "Rising innovative city-regions in a transitional economy: a case study of ICT industry in Cluj-Napoca, Romania", Technology in Society, Vol. 58, p. 101139, doi: 10.1016/j. techsoc.2019.05.003.

Farnese, M.L., Fida, R. and Picoco, M. (2020), "Error orientation at work: dimensionality and relationships with errors and organizational cultural factors", Current Psychology, doi: 10.1007/ s12144-020-00639-x.

Farnese, M., Zaghini, F., Caruso, R., Fida, R., Romagnoli, M. and Sili, A. (2019), "Managing care errors in the wards: the contribution of authentic leadership and error management culture", Leadership \& Organization Development Journal, Vol. 40 No. 1, pp. 17-30.

Ferguson, C.C. (2017), "The emotional fallout from the culture of blame and shame", JAMA Pediatrics, Vol. 171 No. 12, p. 1141.

Fischer, M.A., Mazor, K.M., Baril, J., Alper, E., DeMMaco, D. and Pugnaire, M.D. (2006), "Learning from mistakes factors that influence how students and residents learn from medical errors", Journal of General Internal Medicine, Vol. 21 No. 5, pp. 419-423.

Fornell, C. and Larcker, D.F. (1981), "Evaluating structural equation models with unobservable variables and measurement error", Journal of Marketing Research, Vol. 18 No. 1, pp. 39-50, doi: 10.1177/ 002224378101800104.

Francis, G. (2001), Introduction to SPSS for Windows, 3rd ed., Pearson Education, Sydney, NSW.

Frazier, M.L., Fainshmidt, S., Klinger, R.L., Pezeshkan, A. and Vracheva, V. (2017), "Psychological safety: a meta-analytic review and extension", Personnel Psychology, Vol. 70 No. 1, pp. 113-165.

Frese, M. and Keith, N. (2015), "Action errors, error management, and learning in organizations", Annual Review of Psychology, Vol. 66 No. 1, pp. 661-687.

Fuller, C.M., Simmering, M.J., Atinc, G., Atinc, Y. and Babin, B.J. (2016), "Common methods variance detection in business research", Journal of Business Research, Vol. 69 No. 8, pp. 3192-3198, doi: 10.1016/j.jbusres.2015.12.008.

Gaikwad, P.K., Jayakumar, C.T., Tilve, E., Bohra, N., Yu, W. and Spichkova, M. (2019), "Voice-activated solutions for agile retrospective sessions", Procedia Computer Science, Vol. 159, pp. 2414-2423. 
Ganguly, A., Talukdar, A. and Chatterjee, D. (2019), "Evaluating the role of social capital, tacit knowledge sharing, knowledge quality and reciprocity in determining innovation capability of an organization", Journal of Knowledge Management, Vol. 23 No. 6, pp. 1105-1135.

Garvin, D.A. (1993), "Building a learning organization", Harvard Business Review, Vol. 71 No. 4, pp. 78-91.

Goffin, K. and Koners, U. (2011), "Tacit knowledge lessons learnt and new product development", Journal of Product Innovation Management, Vol. 28 No. 2, pp. 300-318.

Goffin, K., Koners, U., Baxter, D. and van der Hoven, C. (2010), "Managing lessons learned and tacit knowledge in new product development", Research-Technology Management, Vol. 53 No. 4, pp. 39-51, doi: 10.1080/08956308.2010.11657639.

Göksel, A. and Aydintan, B. (2017), "How can tacit knowledge be shared more in organizations? A multidimensional approach to the role of social capital and locus of control", Knowledge Management Research \& Practice, Vol. 15 No. 1, pp. 34-44, doi: 10.1057/kmrp.2015.22.

Guchait, P., Lee, C., Wang, C.Y. and Abbott, J.L. (2016), "Impact of error management practices on service recovery performance and helping behaviors in the hospitality industry: the mediating effects of psychological safety and learning behaviors", Journal of Human Resources in Hospitality \& Tourism, Vol. 15 No. 1, pp. 1-28.

Guchait, P., Paşamehmetoğlu, A. and Lanza-Abbott, J. (2015), "The importance of error management culture in organizations: the impact on employee helping behaviors during service failures and recoveries in restaurants", Journal of Human Resources in Hospitality \& Tourism, Vol. 14 No. 1, pp. 45-67, doi: 10.1080/15332845.2014.904175.

Guchait, P., Zhao, X., Madera, J., Hua, N. and Okumus, F. (2018), "Can error management culture increase work engagement in hotels? The moderating role of gender", Service Business, Vol. 12 No. 4, pp. 757-778.

Hagedoorn, J. and Wang, N. (2012), "Is there complementarity or substitutability between internal and external R\&D strategies?", Research Policy, Vol. 41 No. 6, pp. 1072-1083.

Hagen, J. (2013), Confronting Mistakes: Lessons from the Aviation Industry When Dealing with Error, Springer, doi: 10.1111/j.1525-1497.2006.00420.x.

Hair, J.F., Anderson, R.E., Babin, B.J. and Black, W.C. (2010), Multivariate Data Analysis: A Global Perspective, Pearson Education, Upper Saddle River, NJ.

Harteis, C., Bauer, J. and Gruber, H. (2008), "The culture of learning from mistakes: how employees handle mistakes in everyday work", International Journal of Educational Research, Vol. 47 No. 4, pp. 223-231.

Hayes, A. (2018), Introduction to Mediation, Moderation and Conditional Process Analysis: A RegressionBased Approach, Guilford Press, New York, NY.

Henri, I. (2016), "Review of empirical research on knowledge management practices and firm performance", Journal of Knowledge Management, Vol. 20 No. 2, pp. 230-257.

Hu, L.T. and Bentler, P.M. (1999), "Cutoff criteria for fit indexes in covariance structure analysis: conventional criteria versus new alternatives", Structural Equation Modeling: A Multidisciplinary Journal, Vol. 6 No. 1, pp. 1-55.

Huang, F. and Liu, B. (2017), "Software defect prevention based on human error theories", Chinese Journal of Aeronautics, Vol. 30 No. 3, pp. 1054-1070.

Insch, G.S., McIntyre, N. and Dawley, D. (2008), "Tacit knowledge: a refinement and empirical test of the academic tacit knowledge scale", The Journal of Psychology, Vol. 142 No. 6, pp. 561-580, doi: 10.3200/ JRLP.142.6.561-580.

Islam, T., Khan, S.-R., Ahmad, U.N.U. and Ahmed, I. (2013), "Organizational learning culture and leadermember exchange quality", The Learning Organization, Vol. 20 Nos 4/5, pp. 322-337.

Islam, M.Z., Jasimuddin, S.M. and Hasan, I. (2015), "Organizational culture, structure, technology infrastructure and knowledge sharing", VINE Journal of Information and Knowledge Management Systems, Vol. 45 No. 1, pp. 67-88.

Jiménez-Jiménez, D. and Sanz-Valle, R. (2011), "Innovation, organizational learning and performance", Journal of Business Research, Vol. 64 No. 4, pp. 408-417, doi: 10.1016/j.jbusres.2010.09.010. 
Jiménez-Jiménez, D., Sanz-Valle, R. and Hernandez-Espallardo, M. (2008), "Fostering innovation: the role of market orientation and organizational learning", European Journal of Innovation Management, Vol. 11 No. 3, pp. 389-412, doi: 10.1108/14601060810889026.

Jisr, R.E. and Maamari, B.E. (2017), "Effectuation: exploring a third dimension to tacit knowledge", Knowledge and Process Management, Vol. 24 No. 1, pp. 72-78, doi: 10.1002/kpm. 1536.

Jung, H.S. and Yoon, H.H. (2017), "Error management culture and turnover intent among food and beverage employees in deluxe hotels: the mediating effect of job satisfaction", Service Business, Vol. 11 No. 4, pp. 785-802.

Kaiser, H. (1974), "An index of factor simplicity", Psychometrika, Vol. 39 No. 1, pp. 31-36, doi: 10.1007/ BF02291575.

Kalender, Z.T., Tozan, H. and Vayvay, O. (2020), "Prioritization of medical errors in patient safety management: framework using interval-valued intuitionistic fuzzy sets", Healthcare ( Healthcare), Vol. 8 No. 3, p. 265, doi: 10.3390/healthcare8030265.

Kish, L. (1959), "Some statistical problems in research design", American Sociological Review, Vol. 24 No. 3, pp. 328-338, doi: 10.2307/2089381.

Kodama, M. (2019), "Boundaries knowledge (knowing) - a source of business innovation", Knowledge and Process Management, Vol. 26 No. 3, pp. 210-228, doi: 10.1002/kpm.1603.

Koestler, A. (1971), The Act of Creation, Pan.

Koriat, N. and Gelbard, R. (2014), "Knowledge sharing motivation among IT personnel: integrated model and implications of employment contracts", International Journal of Information Management, Vol. 34 No. 5, pp. 577-591.

Kucharska, W. and Bedford, D.A.D. (2020), "Love your mistakes! they help you adapt to change: how do knowledge, collaboration and learning cultures foster organizational intelligence?", Journal of Organizational Change Management, Vol. 33 No. 7, pp. 1329-1354, doi: 10.1108/JOCM-02-2020-0052.

Kucharska, W. and Erickson, G.S. (2021), "Tacit knowledge awareness, sharing, and influence on innovation: a polish/US cross-country study", International Journal of Information Management.

Kucharska, W. and Kowalczyk, R. (2016), "Trust, collaborative culture and tacit knowledge sharing in project management-a relationship model", Proceedings of the 13th International Conference on Intellectual Capital, Knowledge Management and Organisational Learning (ICICKM), Ithaca, New York, NY, pp. 159-166.

Kurtessis, J.N., Eisenberger, R., Ford, M.T., Buffardi, L.C., Stewart, K.A. and Adis, C.S. (2017), "Perceived organizational support: a Meta-analytic evaluation of organizational support theory", Journal of Management, Vol. 43 No. 6, pp. 1854-1884.

Love, P.E.D., Lopez, R. and Edwards, D.J. (2013), "Reviewing the past learn in the failure: making sense of design errors and failures in construction", Structure and Infrastructure Engineering, Vol. 9 No. 7 , pp. 675-688.

Love, P.E.D., Smith, J. and Teo, P. (2018), "Putting into practice error management theory: unlearning and learning to manage action errors in construction", Applied Ergonomics, Vol. 69, pp. 104-111.

Love, P.E.D., Teo, P., Ackermann, F. and Morrison, J. (2015), "From individual to collective learning: enacting rework prevention in a program water infrastructure alliance", Journal of Construction Engineering and Management, Vol. 141 No. 11, p. 5015009.

McGrath, R.G. (1999), "Falling forward: real options reasoning and entrepreneurial failure", Academy of Management Review, Vol. 24 No. 1, pp. 13-30.

MacKinnon, D.P., Krull, J.L. and Lockwood, C.M. (2000), "Equivalence of the mediation, confounding and suppression effect”, Prevention Science, Vol. 1 No. 4, pp. 173-181, doi: 10.1023/A:1026595011371.

Mabey, C., Kulich, C. and Lorenzi-Cioldi, F. (2012), "Knowledge leadership in global scientific research", The International Journal of Human Resource Management, Vol. 23 No. 12, pp. 2450-2467, doi: 10.1080/ 09585192.2012 .668386$.

Mabey, C. and Zhao, S. (2017), "Managing five paradoxes of knowledge exchange in networked organizations: new priorities for HRM?", Human Resource Management Journal, Vol. 27 No. 1, pp. 39-57, doi: 10.1111/1748-8583.12106. 
Mangels, J.A., Butterfield, B., Lamb, J., Good, C. and Dweck, C.S. (2006), "Why do beliefs about intelligence influence learning success? A social cognitive neuroscience model", Social Cognitive and Affective Neuroscience, Vol. 1 No. 2, pp. 75-86, doi: 10.1093/scan/nsI013.

Manu, F.A. (1992), "Innovation orientation, environment and performance: a comparison of US and European markets", Journal of International Business Studies, Vol. 23 No. 2, pp. 333-359.

Metcalfe, J. (2017), "Learning from errors", Annual Review of Psychology, Vol. 68 No. 1, pp. 465-489, doi: 10.1146/annurev-psych-010416-044022.

Mohsin, S.U., Ibrahim, Y. and Levine, D. (2019), "Teaching medical students to recognise and report errors", BMJ Open Quality, Vol. 8 No. 2, doi: 10.1136/bmjoq-2018-000558.

Mueller, J. (2014), "A specific knowledge culture: cultural antecedents for knowledge sharing between project teams", European Management Journal, Vol. 32 No. 2, pp. 190-202.

Mueller, J.C.Y. (2018), "Effective knowledge management and organisational learning in the context of sustainable development", Electronic Journal of Knowledge Management, Vol. 16 No. 1, pp. 56-69.

Nguyen, V.T., Siengthai, S., Swierczek, F. and Bamel, U.K. (2019), "The effects of organizational culture and commitment on employee innovation: evidence from Vietnam's IT industry", Journal of Asia Business Studies, Vol. 13 No. 4, pp. 719-742, doi: 10.1108/JABS-09-2018-0253.

Nielsen, B.B. and Raswant, A. (2018), "The selection, use, and reporting of control variables in international business research: a review and recommendations", Journal of World Business, Vol. 53 No. 6, doi: 10.1016/j.jwb.2018.05.003.

Nonaka, I. (1994), "A dynamic theory of organizational knowledge creation", Organization Science, Vol. 5 No. 1, pp. 14-37.

Nonaka, I. and Takeuchi, H. (1995), The Knowledge-Creating Company: How Japanese Companies Create the Dynamics of Innovation, Oxford University Press.

Nonaka, I. and Takeuchi, H. (2019), The Wise Company: How Companies Create Continuous Innovation, Oxford University Press.

Olaisen, J. and Revang, O. (2018), "Exploring the performance of tacit knowledge: how to make ordinary people deliver extraordinary results in teams", International Journal of Information Management, Vol. 43, pp. 295-304, doi: 10.1016/j.jijinfomgt.2018.08.016.

Örtenblad, A. (2002), "A typology of the idea of learning organization", Management Learning, Vol. 33 No. 2, pp. 213-230.

Oswald, A.J. and Mascarenhas, S.J. (2019), "The ethics of corporate critical thinking", in: Oswald, A.J. and Mascarenhas, S.J. (Eds), Executive Response to Market Challenges, Emerald Publishing Limited.

Park, S. and Kim, E.-J. (2015), "Revisiting knowledge sharing from the organizational change perspective", European Journal of Training and Development, Vol. 39 No. 9, pp. 769-797.

Parker, S., Racz, M. and Palmer, P. (2020), "Reflexive learning and performative failure", Management Learning, Vol. 51 No. 3, doi: 10.1177/1350507620903170.

Pasamehmetoglu, A., Guchait, P., Tracey, J.B., Cunningham, C.J.L. and Lei, P. (2017), "The moderating effect of supervisor and coworker support for error management on service recovery performance and helping behaviors", Journal of Service Theory and Practice, Vol. 27 No. 1, pp. 2-22, doi: 10.1108/JSTP06-2015-0130.

Pérez-Luño, A., Alegre, J. and Valle-Cabrera, R. (2019), "The role of tacit knowledge in connecting knowledge exchange and combination with innovation", Technology Analysis \& Strategic Management, Vol. 31 No. 2, pp. 186-198.

Pérez-Luño, A., Saparito, P. and Gopalakrishnan, S. (2016), "Small and medium-sized enterprise's entrepreneurial versus market orientation and the creation of tacit knowledge", Journal of Small Business Management, Vol. 54 No. 1, pp. 262-278.

Podsakoff, P.M., MacKenzie, S.B. and Podsakoff, N.P. (2012), "Sources of method bias in social science research and recommendations on how to control it", Annual Review of Psychology, Vol. 63 No. 1, pp. 539-569, doi: 10.1146/annurev-psych-120710-100452.

Podsakoff, P.M. and Organ, D. (1986), "Self-reports in organizational research: problems and prospects”, Journal of Management, Vol. 12 No. 4, pp. 531-544, doi: 10.1177/014920638601200408.

Polanyi, M. (1966), The Tacit Dimension, University of Chicago Press, Chicago, IL. 
Politis, D. and Gabrielsson, J. (2009), "Entrepreneurs' attitudes towards failure: an experiential learning approach", International Journal of Entrepreneurial Behavior \& Research, Vol. 15 No. 4, pp. 364-383.

Powell, W.W. and Snellman, K. (2004), "The knowledge economy", Annual Review of Sociology, Vol. 30 No. 1, pp. 199-220.

Raudenska, P. (2020), "The cross-country and cross-time measurement invariance of positive and negative affect scales: evidence from European social survey", Social Science Research, p. 102369, doi: 10.1016/j.ssresearch.2019.102369.

Rebelo, T. and Gomes, A.D. (2011a), "Conditioning factors of an organizational learning culture", Journal of Workplace Learning, Vol. 23 No. 3, pp. 173-194, doi: 10.1108/13665621111117215.

Robertson, J.J. and Long, B. (2018), "Suffering in silence: medical error and its impact on health care providers", The Journal of Emergency Medicine, Vol. 54 No. 4, pp. 402-409, doi: 10.1016/j. jemermed.2017.12.001.

Rothberg, H.N. and Erickson, G.S. (2017), "Big data systems: knowledge transfer or intelligence insights?", Journal of Knowledge Management, Vol. 21 No. 1, pp. 92-112, doi: 10.1108/JKM-07-20150300 .

Rutten, W., Blaas-Franken, J. and Martin, H. (2016), "The impact of (low) trust on knowledge sharing", Journal of Knowledge Management, Vol. 20 No. 2, pp. 199-214.

Ryan, S. and O'Connor, R.V. (2013), "Acquiring and sharing tacit knowledge in software development teams: an empirical study", Information and Software Technology, Vol. 55 No. 9, pp. 1614-1624.

Saint-Onge, H. (1996), "Tacit knowledge the key to the strategic alignment of intellectual capital", Planning Review, Vol. 24 No. 2, pp. 10-16, doi: 10.1108/eb054547.

Sakellariou, E., Karantinou, K. and Goffin, K. (2017), "Telling tales: stories. metaphors and tacit knowledge at the fuzzy front-end of NPD", Creativity and Innovation Management, Vol. 26 No. 4, pp. 353-369, doi: 10.1111/caim.12237.

Seckler, Ch, Gronewold, U. and Reihlen, M. (2017), "An error management perspective on audit quality: toward a multi-level model”, Accounting, Organizations and Society, Vol. 62, pp. 21-42.

Seifried, J. and Höpfer, E. (2013), "The perception of error in production plants of a chemical organisation”, Vocations and Learning, Vol. 6 No. 2, pp. 159-185, doi: 10.1007/s12186-012-9081-1.

Senders, J.W. and Moray, N.P. (1991), Human Error: Cause, Prediction, and Reduction, CRC Press, Taylor \& Francis Group.

Senge, P.M. (2006), The Fifth Discipline: The Art \& Practice of the Learning Organization, Crown Business, New York, NY.

Sheng, M.I. (2019), "Foreign tacit knowledge and a capabilities perspective on MNEs' product innovativeness: examining source-recipient knowledge absorption platforms", International Journal of Information Management, Vol. 44, pp. 154-163, doi: 10.1016/j.ijinfomgt.2018.10.008.

Shepherd, D.A. (2003), "Learning from business failure: propositions of grief recovery for the selfemployed", The Academy of Management Review, Vol. 28 No. 2, pp. 318-328.

Simonsson, C. and Heide, M. (2018), "How focusing positively on errors can help organizations become more communicative: an alternative approach to crisis communication", Journal of Communication Management, Vol. 22 No. 2, pp. 179-196, doi: 10.1108/JCOM-04-2017-0044.

Singh, M. and Walia, G.S. (2020), "Using semantic analysis and graph mining approaches to support software fault fixation", 2020 IEEE International Symposium on Software Reliability Engineering Workshops (ISSREW), doi: 10.1109/ISSREW51248.2020.00035.

Spector, P.E. and Brannick, M.T. (2011), "Methodological urban legends: the misuse of statistical control variables", Organizational Research Methods, Vol. 14 No. 2, pp. 287-305, doi: 10.1177/ 1094428110369842

Srirama, M.V., Iyer, P.P. and Reddy, H. (2020), "Dimensions of social capital and learning culture: a case of an IT organization", The Learning Organization, Vol. 27 No. 4, pp. 337-349.

Statistics Poland (2017), "Polish yearbook of labour statistics", available at: https://stat.gov.pl/en/topics/ statisticalyearbooks/statistical-yearbooks/yearbook-of-labour-statistics-2017,10,6.html (accessed 15 July 2020). 
Tripathi, A., Srivastava, R. and Sankaran, R. (2020), "Role of learning agility and learning culture on turnover intention: an empirical study", Industrial and Commercial Training, Vol. 52 No. 2, pp. 105-120, doi: 10.1108/ICT-11-2019-0099.

Tucker, L.R. and Lewis, C. (1973), "A reliability coefficient for maximum likelihood factor analysis", Psychometrika, Vol. 38 No. 1, pp. 1-10.

Van Dyck, C., Dimitrova, N.G., De Korne, D.F. and Hiddema, F. (2013), "Walk the talk: leaders' enacted priority of safety, incident reporting, and error management", Leading in Health Care Organizations: Improving Safety, Satisfaction and Financial Performance, Vol. 14, pp. 95-117.

Van Dyck, C., Frese, M., Baer, M. and Sonnentag, S. (2005), "Organizational error management culture and its impact on performance: a two-study replication", Journal of Applied Psychology, Vol. 90 No. 6, pp. 1228-1240.

Vanderheiden, E. and Mayer, C.-H. (2020), Mistakes, Errors and Failures across Cultures, Springer.

Waeschle, R.M., Bauer, M., Schmidt, C.E., et al. (2015), "Errors in medicine: causes, impact and improvement measures to improve patient safety", Der Anaesthesist, Vol. 64 No. 9, pp. 689-704.

Wang, X., Guchait, P. and Paşamehmetoğlu, A. (2020), "Tolerating errors in hospitality organizations: relationships with learning behavior, error reporting and service recovery performance", International Journal of Contemporary Hospitality Management, Vol. 32 No. 8, pp. 2635-2655, doi: 10.1108/IJCHM-012020-0001.

Weinzimmer, L.G. and Esken, C.A. (2017), "Learning from mistakes: how mistake tolerance positively affects organizational learning and performance", The Journal of Applied Behavioral Science, Vol. 53 No. 3, pp. 322-348.

Wong, S. and Chin, K. (2007), "Organizational innovation management: an organization-wide perspective", Industrial Management \& Data Systems, Vol. 107 No. 9, pp. 1290-1315, doi: 10.1108/ 02635570710833974.

Yamakawa, Y. and Cardon, M.S. (2015), "Causal ascriptions and perceived learning from entrepreneurial failure", Small Business Economics, Vol. 44 No. 4, pp. 797-820.

Zappa, P. and Robins, G. (2016), "Organizational learning across multi-level networks", Social Networks, Vol. 44, pp. 295-306.

Zhao, B. and Olivera, F. (2006), "Error reporting in organizations", Academy of Management Review, Vol. 31 No. 4, doi: 10.5465/amr.2006.22528167.

Zinn, J.O. (2020), Understanding Risk-Taking: Critical Studies in Risk and Uncertainty, Palgrave Macmillan, Cham.

\section{Further reading}

Love, P.E.D. and Smith, J. (2016), "Toward error management in construction: moving beyond a zero vision", Journal of Construction Engineering and Management, Vol. 142 No. 11, p. 04016058, doi: 10.1061/(ASCE)CO. 1943-7862.0001170.

\section{Corresponding author}

Wioleta Kucharska can be contacted at: wioleta.kucharska@pg.edu.pl

For instructions on how to order reprints of this article, please visit our website: www.emeraldgrouppublishing.com/licensing/reprints.htm

Or contact us for further details: permissions@emeraldinsight.com 